stake of American University of Antigua and entered the Caribbean medical market in 2008 and soon plans to enter Oman, Indonesia, and Vietnam. The group's international operations contribute to more than 50 percent of its revenue.

From targeting foreign students when it began, the Punebased Symbiosis that started in I97I has 33 institutions in 9 campuses, enrolling 45,000 students on campus and I00,000 students in distance-learning programs. It was granted deemed-university status in 2002 . In recognition of the fact that it enrolls students from over 60 countries, the institution renamed itself as the Symbiosis International University in 2006. The Apeejay Education Society, which started with schools about 40 years ago and later expanded into higher education, has I3 institutions of higher education enrolling 32,000 students in 80 courses across the country.

\section{New Initiatives}

The Institute of Chartered Financial Analysts of India (ICFAI) was established in 1984 to impart training in finance and management to students, working executives and professionals, and the CFA Program (popular abroad) in I985. It now has seven private universities in Uttarakhand, Tripura, Sikkim, Meghalaya, Mizoram, Nagaland, and Jharkhand under its fold, and another three are planned in Rajasthan, Chhattisgarh, and Punjab. Each university is a separate and independent legal entity and offers programs at bachelor's and master's levels at a full-time campus and through flexible learning formats in a wide range of subjects. Though a late entrant, the ICFAI universities have now become the largest chain of universities with pan-India presence, enrolling several hundred thousand students.

Amity University, which started just a decade ago, has two universities and 70 institutions that cater to 50,000 students in I30 different programs, from sciences to humanities to media. It has spent around US\$220 million so far, plans to invest around $\$ 450$ million in the next two to three years and to increase the student intake to 500,000 in the next five years. It claims to have consistently grown at 50 percent annually for the past five years and plans to double every year now — both in terms of student intake and revenues.

Coimbatore-based PSG Group, which has io colleges with an enrollment of 16,992 students, expects to establish a university soon. The Bengaluru-based Jain Group has 2I education institutions with an aggregate enrollment of $\mathrm{I} 6,400$ students and I,750 employees and plans Ioo colleges within the next Io years.

In each state or region, new chains of institutions are emerging. Even the states that were laggard in private professional education have embraced private growth for pragmatic reasons. West Bengal has the Techno-India Group, with I4 professional institutions including institutions at Mumbai, Delhi, and Bengaluru under its fold.

\section{Future of Private Chains}

The operation of private institutions tied together in a chain is dictated by operational efficiency and marketing strategy. Such institutions are put together under one brand name. This is not just a marketing ploy but also a strategy that declares their product is working and can now be offered, through institutional cloning, to populations that cannot reach the initial places.

Though only some of the multiple sites may have some autonomy, the core idea is a rather standard package for curriculum, pedagogy, hiring, and admissions to attain higher operational efficiency. As the chains expand nationally, they tend to use an operational management framework for general business organizations by adopting standardized processes.

In such institutions the main source of funding-both to meet recurrent costs and capital costs for expansion-come largely from fees. Due to economies of scale and growing demand, they are able to generate huge surpluses from their operations. Most of the revenues are ploughed back in expansion and consolidation since the Indian tax laws bind the nonprofits to reinvest rather than share their surplus among promoters. As a result, such chains of institutions would keep on expanding and would be a force to reckon with in the Indian higher education in the times to come.

\section{Private Higher Education in Colombia: Problems and Achievements}

\section{LINA URIBE}

Lina Uribe is a doctoral research associate in the Program for Research on Private Higher Education, at the University at Albany, State University of New York and the rector of the Institución Universitaria de Comfacauca in Colombia.E-mail: lu625667@albany.edu.

IHE devotes a column in each issue to a contribution from PROPHE, the Program for Research on Private Higher Education, headquartered at the University at Albany. See http://www.albany.edu/.

$\mathrm{W}$ ithin the Latin American context, Colombia has long been a country leader in diversified private higher education development. In fact, during its history Colombian higher education has had as much as a 68 percent private sector, historically paralleled only by Brazil and in recent decades by Chile. The private institutions became Colombia's majority sector in 1975, but already during the I96os this part of the system was striking for its size. Today, private enrollment represents almost half of total national enrollment. A decline from 
I997 to 2007 may be only short term as the Ministry of Education data show private growth outpacing public growth in 2008.

Private institutions are much more than twice the number of public ones, I97 out of the total 279 officially registered. These institutions are characterized by enormous diversity in size, objectives, and levels. This trend has assisted increased access for the low-income population and the fulfillment of various functions and goals. Nevertheless, quality has become a concern notably in a system that relies so much on the private sector. Whatever the mix of problems and achievements explored below, the significant weight of Colombia's private sector should first be understood as owing much to broad political-historical tendencies and public policies.

Private institutions are much more than twice the number of public ones, 197 out of the total 279 officially registered.

\section{Secular and Religious In itiatives}

Colombian higher education was first influenced by the educational culture inherited from Spain. The first universities in Colombia were mainly private, basically more than in other colonies; they were founded by Catholic orders, while becoming more controlled by the Spanish crown during the late colonial period. Some of these leading institutions are today's Universidad de Santo Tomás (I580), the Universidad Pontificia Javeriana (1623), and the Universidad del Rosario (I653).

As the liberators fought for national independence, they created national public universities to promote the consolidation of the republic. However, private initiatives also expanded, whether by partisan enterprises amid the struggles to steer the new state or by intellectuals who advocated secular, nonreligious, and apolitical institutions. Whereas conservative leaders were likely to give to the Church a fundamental role in education, liberals reacted to conservatism by creating new secular higher education institutions.

In the second half of the 2oth century, private higher education expanded from a system exclusively for the elite to one accommodating part of the increased demand of middle classes. Colombia became a Latin American leader in the number of nonelite institutions.

\section{State Promotion of the Private Sector}

Expansion and diversity have also been promoted by policy initiatives. Given the financial concerns against greatly enlarging the public sector, the Colombian government supports private higher education's ability to absorb the demand in both universities and nonuniversity institutions. Indeed, for decades, the major "public policy" for the expansion of private higher education was simply a lack of investment to expand public higher education.
An analysis of the latest reforms suggests that Colombian public policy has become more proactive and, albeit belatedly, concerned with academic quality. Along with a complex quality-assurance system adopted since 200I, the government has developed tools to stimulate the private initiative in open competition for public funds, by supporting projects to increase quality while achieving enrollment goals. Due to the recent nature of those policies, whether they can effectively address structural quality problems in the lowest-layer institutions remains to be seen.

\section{Institutional Diversity, Massification, and Quality}

About I5 percent of Colombian private universities are founded by religious communities, but the system also shows industry-tied and intellectual enterprises in the founding of private institutions by origin. Many private nonelite institutions are family owned, with a critical ambivalence between the desire for economical earnings and the Colombian legislation that disallows for-profit forms. The practices of some family members for financial gains through positions and high salaries within institutions and arrangements to rent buildings to their own universities are obviously the target of criticisms. Such practices may not only hurt revenues and sustainability of institutions but are also pathways for owners to evade tax payment under the false "nonprofit" cover.

The phenomenon of massification has also created varied

The phenomenon of massification has also created varied types of private higher education institutions regarding legitimacy and quality, ranging from bottom-tier to semielite or locally elite private institutions.

types of private higher education institutions regarding legitimacy and quality, ranging from bottom-tier to semielite or locally elite private institutions. As in other country systems, policies for expanded access have led in Colombia to the unavoidable problem of low academic quality at the bottom of a stratified system. As the system has achieved a 62 percent absorption rate of high school graduates (against 37\% in 2002, according to the World Bank), many institutions house students with poor academic backgrounds. In Colombia, the typical trade-off of access and quality into private higher education shows selective universities characterized by high-quality education alongside less-selective institutions.

Some crucial factors related to the troublesome quality of private bottom-tier institutions include the lack of management tools such as budgets or development plans and the scarcity of full-time professors. Many of those shoddy institutions depend on moonlighting public university professors, 
often teaching in more than one private university. Bottom-tier institutions in Colombia have problems in hiring and paying professors, and some operate in rented buildings poorly adequate for teaching or research. Of course, along with control efforts by the government to change the problematic patterns there are several worthy endeavors of institutions in the middle, searching simultaneously for access and quality.

\section{In Pursuit of Quality}

In contrast to the troublesome features, Colombian private higher education has led the movement into voluntary highquality accreditation. Private institutions constitute the majority of institutions $(63 \%)$ in obtaining such accreditation according to the National Commission of Accreditation data. About a dozen of those private accredited universities might be classified as the leading ones, characterized as well by their offer of doctoral degrees especially in health, law, and social sciences and having a well-trained faculty.

\section{Colombian private higher education has led the} movement into voluntary high-quality accreditation.

Truly, no Colombian higher education institution appears in the research-oriented world rankings-such as the Times Higher Education/QS or the Shanghai Jiao Tong rankings. The leading private Universidad de Los Andes is the only institution registered within the top 500 on the World Universities' rankings (Webometrics.info) according to the visibility, volume, and quality of its electronic publications. The Universidad de Los Andes also has the greatest number of doctorate programs within the private sector.

Although such classifications are quite inexact, perhaps an additional 30 of the five-year private institutions hold national or regional prestige because of accredited programs recognized by the public and the academic community at the undergraduate level. More clearly "demand-absorbing" units could be found in another 74 institutions. Along with them, 8I nonuniversity private institutions offer two-and-three-year programs. As only few of the Colombian "demand-absorbing” and nonuniversity institutions have accredited programs, their quality and legitimacy rest more in holding the "basic conditions of quality." These conditions are mandatory for all Colombian higher education institutions assessed by academic peers and the Ministry of Education as part of the qualityassurance system.

\section{Undergraduate Teaching Evaluation in China: Progress and Debate}

\section{KAI JIANG}

Kai Jiang is an associate professor at the Graduate School of Education, Peking University. Address: Graduate School of Education, Peking University, Beijing 100871, China. E-mail: kjiang@pku.edu.cn.

China has experienced dramatic higher education expansion during the past decade. In comparison with the previous year, the number of students admitted to higher education increased by 47 percent in I999, which again increased by 25 percent in 2000 . In 2002 , the relevant age group participating in higher education reached I5 percent, compared with 5 percent in I993. With more than 27 million students, China's current higher education system is the largest one in the world.

Under the context of rapid expansion, priority has been placed on quantitative growth. Universities, especially local universities were encouraged by the government to enroll more students. Meanwhile, the quality of higher education came to be somewhat neglected. Forgetting about quality caused many problems, such as decline of educational expense per student, deteriorating teaching conditions, and employment difficulty for colleges graduates. Education quality has been questioned by employers, academics, and the public. The government worries that without rigid quality assurance, the expansion itself may not improve national and individual competitiveness.

Currently, the priority of higher education has shifted from quantity growth to quality enhancement. Quality is now being seriously considered by China's government and universities.

\section{MAJOR INITIATIVE}

A key measure for China to guarantee quality is the national evaluation of colleges and universities. In I994, the Department of Higher Education of the Ministry of Education initiated a pilot project on undergraduate teaching evaluation and followed this with two other such evaluations in I996 and I999. The results indicated that higher education institutions under evaluation tended to improve their campus and teaching facilities, increase educational spending, closely monitor teaching quality, and put emphasis on teaching.

The landmark of evaluation is the establishment of the Higher Education Evaluation Center (HEEC) of the ministry (http://www.pgzx.edu.cn) in 2004. During its first five-year cycle, HEEC implemented an undergraduate teaching evaluation for 589 colleges and universities. Although it is to be developed as a comprehensive quasi-government evaluation agency, HEEC starts its work with the national evaluation of 